\title{
Description of a new species of armored spider from Myanmar (Araneae: Tetrablemmidae)
}

\author{
FACUNDO M. LABARQUE \& CRISTIAN J. GRISMADO \\ División Aracnología, Museo Argentino de Ciencias Naturales "Bernardino Rivadavia” - CONICET, Av. Angel Gallardo 470 \\ C1405DJR, Buenos Aires, Argentina.E-mail:facundo_labarque@macn.gov.ar
}

The Tetrablemmidae is a family of small to very small haplogyne, ecribellate, three-clawed spiders characterized mainly by the complex pattern of abdominal scuta (with dorsal, lateral and ventral plates) which justifies their common name “armoured spiders" (Shear 1978, Lehtinen 1981, Jocqué \& Dippenaar-Schoeman 2006). They have a dorsal shield of prosoma heavily sclerotized, usually with rugous, pitted or reticulated surface, distinctly modified in the males of many genera. They lack direct eyes (anterior median), and several genera may lack some or all of the indirect eyes as well. One of the recognized tribes, Tetrablemmini (subfamily Tetrablemminae), contains the type genus of the family: Tetrablemma O. Pickard-Cambridge typically known by having four eyes displaced posteriorly in males, which have a convex clypeus, sometimes with tubercles, and chelicerae with anterior horns (Figs 6, 8-9; Lehtinen 1981: 56; Tong \& Li 2008; Burger 2008).

We examined a small series of a Tetrablemma species collected in Myanmar which does not belong to any of the previously known species. The aim of this contribution is to describe this new species.

Specimens are deposited in the California Academy of Sciences (CAS, Charles E. Griswold). Female internal genitalia were digested in $\mathrm{KOH}$ as in Platnick et al. (1999). Drawings were made with camera lucida mounted on a compound microscope Olympus BH-2. Photographs of the preserved specimens were taken with a digital camera Nikon DXM1200 mounted on a stereomicroscope Nikon SMZ1500 and the extended focal range images composed with Helicon Focus 3.10.3 and 4.01 Pro (Khmelik et al. 2006). The format of descriptions follows mostly Lehtinen (1981). Measurements are expressed in millimeters.

\section{Taxonomy}

Tetrablemma thamin, n. sp.

(Figs 1-11)

Type material: Male holotype and female paratype from Myanmar, Magwe Division, Shwesettaw Wildlife Reservation, N2005'51.1”, E94³3'24.5”, elev. 450 m, deciduous forest, under rocks, 28.-29.IX.2003, leg. D. Ubick, deposited in CAS (CASENT 9017092). (Holotype voucher codes ARAMR000301, preparation codes CJG-00119, FML-00574; paratype voucher codes ARAMR000300, preparation codes CJG-00120, FML-00575).

Additional material examined: Same data as the types, 2 males, 8 females and one juvenile (CAS; voucher codes ARAMR000120, 125, 838, 862; preparation codes CJG-00116, CJG-00127, FML-00281-289).

Etymology: The specific name is a noun in apposition that refers to the thamin deer (Cervus eldi thamin), an endangered cervid typical of Myanmar, protected in the Shwesettaw Wildlife Reservation. The long and curved cheliceral horns of the males resemble the frontal branches of the horns of thamin males.

Diagnosis: Males of Tetrablemma thamin n. sp. resemble those of T. brevidens Tong \& Li and T. magister Burger by the pear-shaped copulatory bulb and the shape of the embolus (Fig. 1; Tong \& Li 2008: figs. 5 G-H; Burger 2008: fig. 19). However, T. thamin n. sp. can be distinguished from both species by having two acute retrolateral processes at the base of the embolus instead of a blunt process or inconspicuous one respectively (Fig. 3; Tong \& Li 2008: fig. 5 F; Burger 2008: fig. 19). Also they can be distinguished by the shape of cheliceral horns (Figs. 8-9; Tong \& Li 2008: fig. 5 C; Burger 2008: figs. 15, 18), and the prosoma reticulated pattern, which in T. thamin n. sp. present some smooth areas, not as in the other two species. Females of T. thamin n. sp. resemble those of T. vietnamensis Lehtinen, T. brevidens and 
T. magister by their relatively large size, the pattern of abdominal scuta, the transverse furrows on the epigynal area (Figs 2, 11; Lehtinen 1981: figs 275, 286; Tong \& Li 2008: fig. 5 D-E; Burger 2008: fig. 22, 25). T. thamin n. sp. can be distinguished from T. vietnamensis, T. brevidens and T. magister by its inconspicuous central vulval process (Fig. 2) and by its shorter and broader postgenital ventral plate (Figs 2, 11).
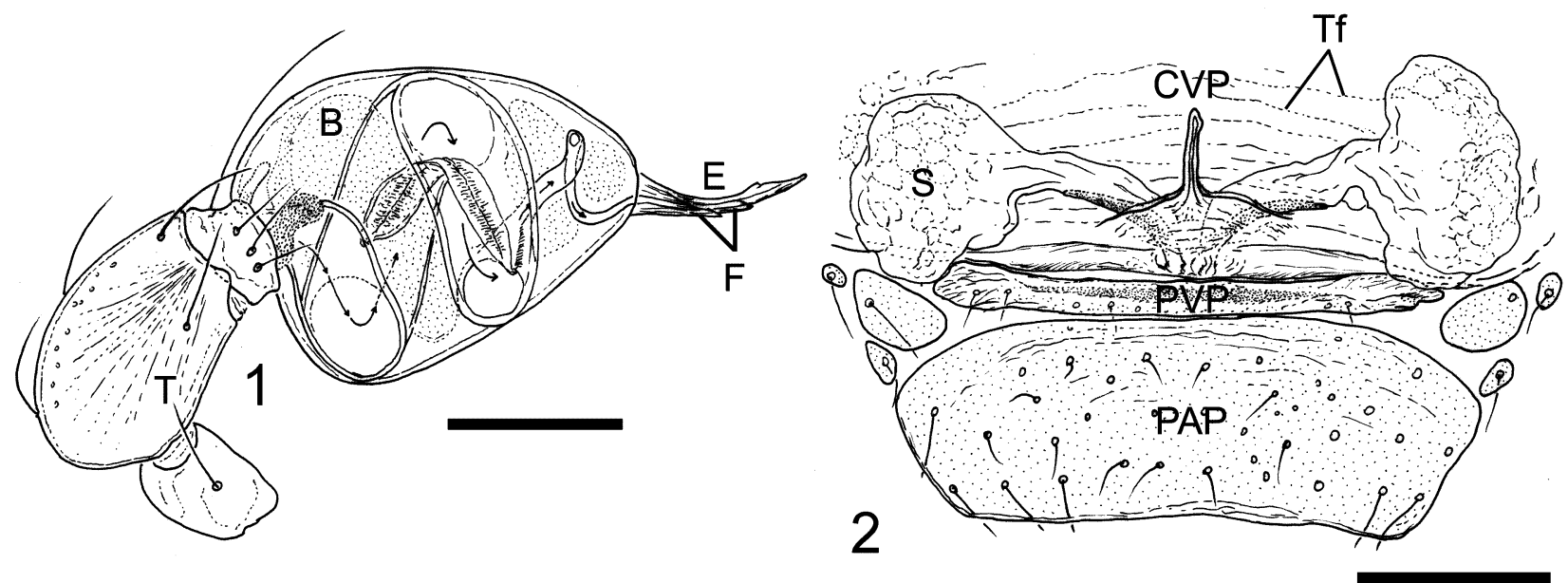

FIGURES 1-2. Tetrablemma thamin n. sp. Genitalia. 1 male right palp, retrolateral view (ARAMR000120); 2 female vulva, dorsal view (ARAMR000125). Abbreviations: (ARP) acute retrolateral processes, (B) bulb, (E) embolus, (IVP) inner vulval plate, (PAP) pre-anal plate, (PVP) postgenital ventral plate, $(\mathrm{S})$ seminal receptacle, $(\mathrm{T})$ tibia, $(\mathrm{Tf})$ transverse furrow. Scale bars: $100 \mu \mathrm{m}$.
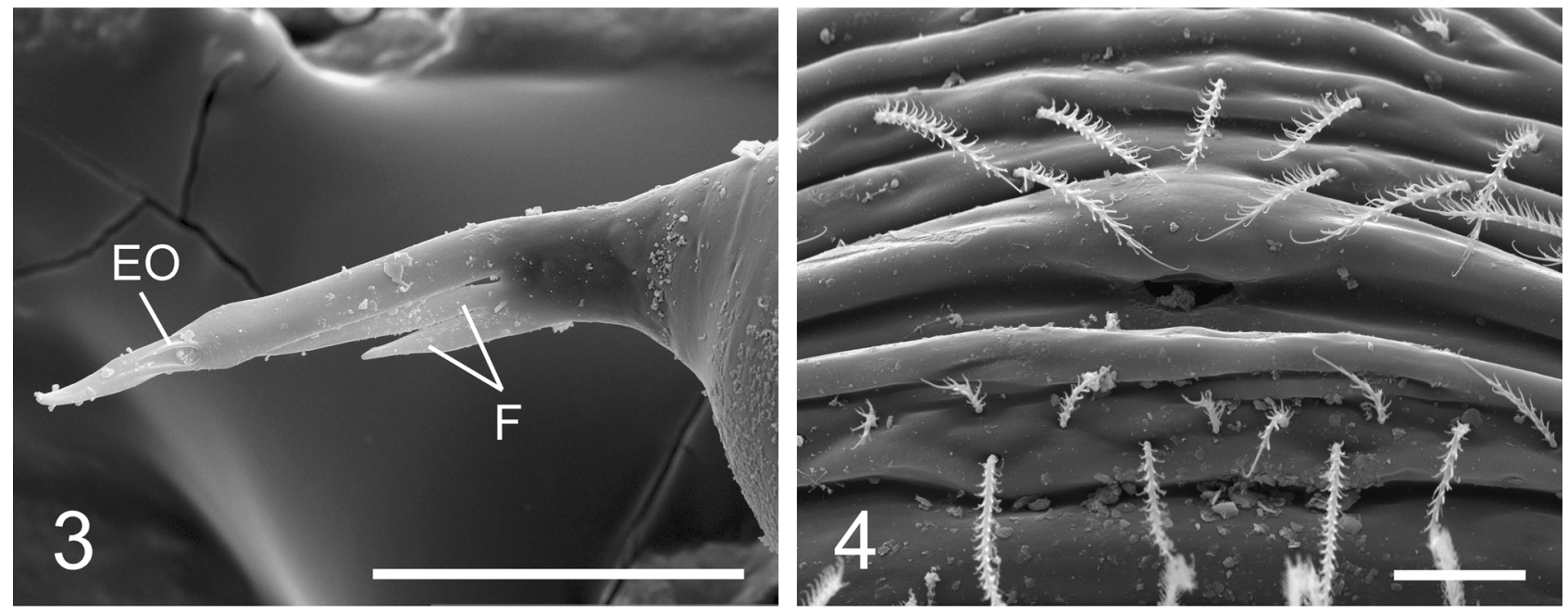

FIGURES 3-4. Tetrablemma thamin n. sp. Genitalia. 3 male left palp, embolus detail, dorsal view (ARAMR000120); 4 female genitalia, detail of genital opening, ventral view (ARAMR000838). Abbreviations: (ARP) acute retrolateral processes, (SO) subterminal outlet. Scale bars: $150 \mu \mathrm{m} ; 220 \mu \mathrm{m}$.

Description. Male (CASENT 9017092): Total length 1.14. ALE>PLE, PLE separated by about one diameter; dorsal shield of prosoma covered with fine reticulated pattern, except in front and above the ocular areas, and in several thin smooth radial areas (Figs 6,8). Anterior hump of the clypeus without tubercles, but with a pair of setae. Cheliceral horns long, relatively narrow, tip pointing backwards (Figs 8-9). Dorsal abdominal scutum long, oval, finely reticulate except by several sparse smooth rounded areas (Fig. 6). All sclerotized integuments orange (Fig. 6-7, 9). Palp: copulatory bulb pear-shaped; thread-like embolus with two acute retrolateral process at its base, and subterminal outlet (Figs. 1, 3).

Female (CASENT 9017092): Total length 1.18. Cephalic area horizontal, with acute process projecting posteriorly. AME $>$ PLE, PLE separated by more than one diameter (Fig. 10, traces of PME visible by transparence); dorsal shield of 
prosoma with reticulate pattern similar as in male. Abdominal ventral scuta as in T. vietnamensis, T. brevidens and T. magister (Lehtinen 1981: fig. 275; Tong \& Li 2008: fig. 5 D; Burger 2008: fig. 22), but postgenital plate shorter and broader, epigynal area with shallow transverse furrows and a dark pit (Fig. 11). Vulva: a single oval genital opening leading into a paired sclerotised copulatory ducts (Fig. 4); central vulval process inconspicous; inner vulval plate triangular with a central branch; seminal receptacles with folded cuticle (Fig. 2). Color as in male.
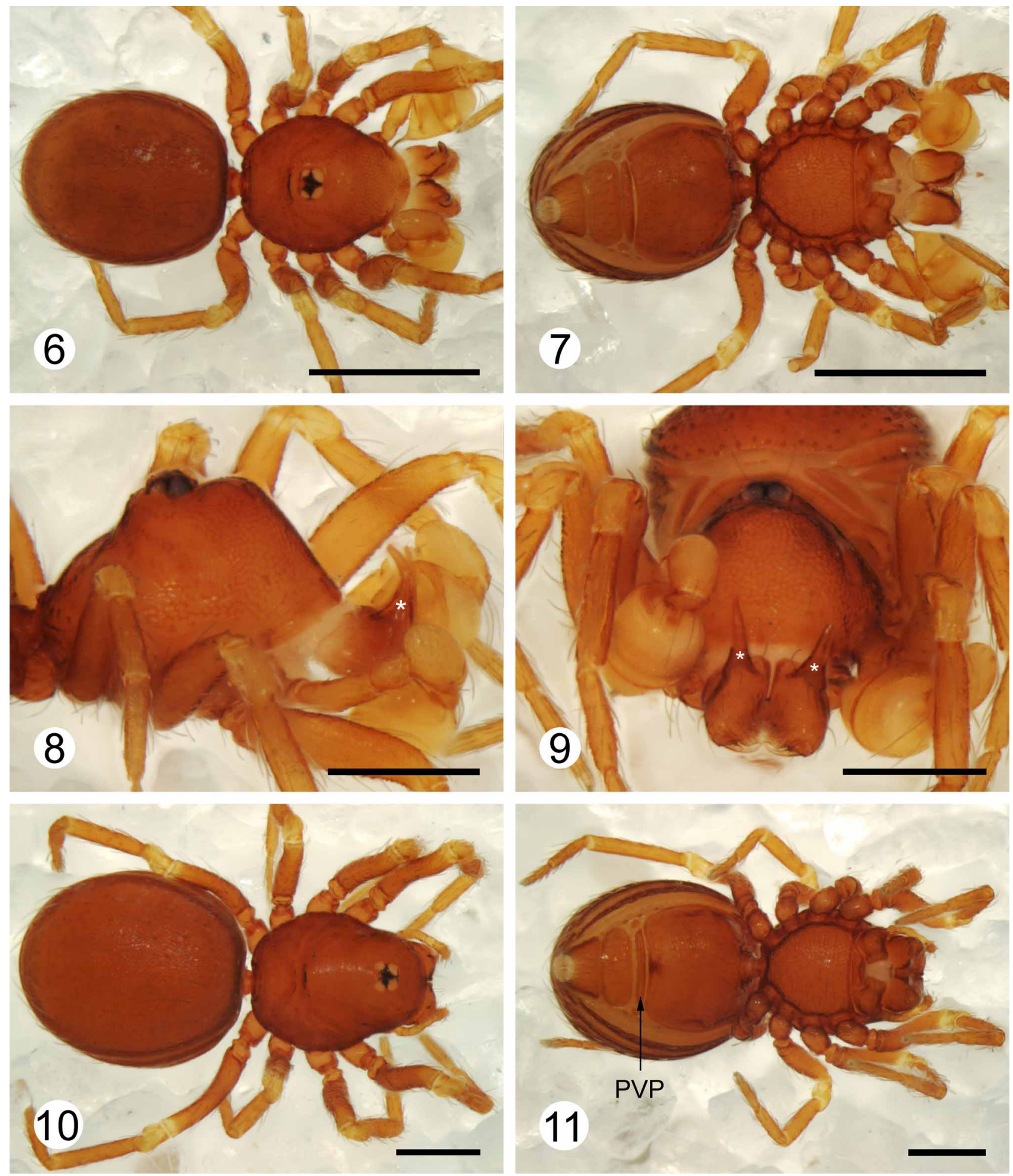

FIGURES 6-11. Tetrablemma thamin n. sp. Preserved specimens. 6-9 male holotype (ARAMR000301) (6 dorsal, 7 ventral habitus, 8 prosoma lateral, * in horn, 9 ditto, frontal). 10-11 female paratype (ARAMR000300) (10 dorsal, 11 ventral habitus). Abbreviations: (PVP) postgenital ventral plate. Scale bars: $6-7=0.5 \mathrm{~mm}, 8-11=0.25 \mathrm{~mm}$. 
Distribution. Only known from Myanmar.

Life history and habitat preferences. According to the labels, all the known specimens were found under stones, in a deciduous forest.

Remarks. The posterior position of the male eye group and convex clypeus suggest that Tetrablemma thamin $\mathbf{n}$. sp. may belong to either subgenera Tetrablemma or Indonops (Lehtinen, 1981). The absence of modifications in the male first metatarsi or undulations on the copulatory bulb suggests that it may belong to the subgenus Indonops rather than Tetrablemma. Within Indonops, the presence of transverse epigynal furrows suggest that T. thamin $\mathbf{n}$. sp. belongs to the marawula species group, which includes T. marawula Lehtinen, T. manggarai Lehtinen, T. mardionoi Lehtinen, T. vietnamensis, T. pulchoki Lehtinen, and probably the recently described T. brevidens and T. magister. The retrolateral processes at the base of the embolus suggest that this two latter species are closest to T. thamin $\mathbf{n}$. sp.

\section{Acknowledgements}

We wish to thank Martín Ramírez for an early revision of this manuscript, to the journal editor Milan Rezác and to an anonymous reviewer. We also wish to thank Darrel Ubick and Charles Griswold for collected and loaned the specimens of the new species. This work was supported by grants EAR-0228699 from NSF, PICT 14092 from ANPCyT and PIP 6502 from CONICET to Martín Ramírez (Museo Argentino de Ciencias Naturales), and a doctoral fellowship from CONICET to Facundo Labarque.

\section{References}

Burger, M. (2008) Two new species of armoured spiders from Malaysia and Australia (Arachnida: Araneae: Tetrablemmidae). Bulletin of British arachnological Society, 14 (6), 253-261.

Helicon Focus 3.10.3 and 4.01 Pro [Internet] Khmelik, V.V., Kozub, D. \& Glazunov, A. (2006), Available from: http:// helicon.com.ua/heliconfocus/

Jocqué, R. \& Dippenaar-Schoeman, A.S. (2006) Spider families of the world. Royal Museum for Central Africa, Tervuren, $336 \mathrm{pp}$.

Lehtinen, P.T. (1981) Spiders of the Oriental-Australian region. III. Tetrablemmidae, with a world revision. Acta Zoologica Fennica, 162, 1-151.

Platnick, N.I., Grismado, C.J. \& Ramírez, M.J. (1999) On the genera of the spider subfamily Otiothopinae (Araneae, Palpimanidae). American Museum Novitates, 3257, 1-25.

Ramírez, M.J. (2000) Respiratory system morphology and the phylogeny of haplogyne spiders (Araneae, Araneomorphae). Journal of Arachnology, 28, 149-157.

Shear, W.A. (1978) Taxonomic notes on the armored spiders of the families Tetrablemmidae and Pacullidae. American Museum Novitates, 2650, 1-46.

Tong, Y. \& Li, S. (2008) Tetrablemmidae (Arachnida, Araneae), a spider family newly recorded from China. Organisms, Diversity \& Evolution, 8, 84-98. 